\title{
The role of repeat infection in the dynamics of a simple model of waning and boosting immunity
}

\author{
Laura F. Strube \\ Virginia Polytechnic Institute and State University, Ifstrube@gmail.com \\ Maya Walton \\ Virginia Polytechnic Institute and State University \\ Lauren M. Childs \\ Virginia Polytechnic Institute and State University, Ichilds@vt.edu
}

Follow this and additional works at: https://scholarscompass.vcu.edu/bamm

Part of the Life Sciences Commons, Medicine and Health Sciences Commons, and the Physical Sciences and Mathematics Commons

https://scholarscompass.vcu.edu/bamm/2020/talk/12

This Event is brought to you for free and open access by the Dept. of Mathematics and Applied Mathematics at VCU Scholars Compass. It has been accepted for inclusion in Biology and Medicine Through Mathematics Conference by an authorized administrator of VCU Scholars Compass. For more information, please contact libcompass@vcu.edu. 


\title{
The role of repeat infection in the dynamics of a simple model of waning and boosting immunity
}

\begin{abstract}
Some infectious diseases produce lifelong immunity while others only produce temporary immunity. In the case of short-lived immunity, the level of protection wanes over time and may be boosted upon re-exposure, via infection or vaccination. Previous work developed a simple model capturing waning and boosting immunity, known as the Susceptible-Infectious-Recovered-Waned-Susceptible (SIRWS) model, which exhibits rich dynamical behavior including supercritical and subcritical Hopf bifurcations among other structures. Here, we extend the bifurcation analyses of the SIRWS model to examine the influence of all parameters on these bifurcation structures. We show that the bistable region, involving both a stable fixed point and a stable limit cycle, exists only for a small region of biologically realistic parameter space. Furthermore, we contrast the SIRWS model with a modified version, where immune boosting depends on the occurrence of a secondary infection. Analysis of this extended model shows that oscillations and bistability, as found in the SIRWS model, depend on strong assumptions about infectivity and recovery rate of secondary infection. Understanding the dynamics of models of waning and boosting immunity is important for accurately assessing epidemiological data.
\end{abstract}

